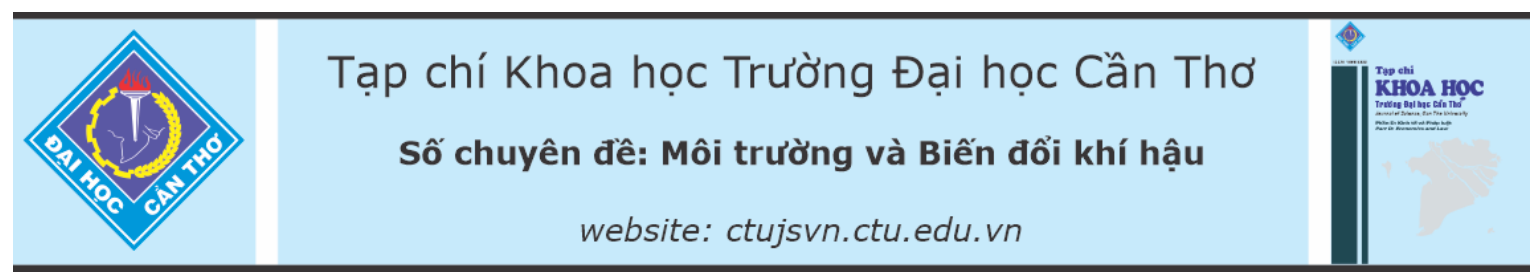

DOI:10.22144/ctu.jsi.2021.058

\title{
ĐÁNH GIÁ THỤCC TRẠNG KHÔ HẠN TẠI TỈNH BẾN TRE
}

\author{
Mai Xuân* và Lê Tấn Lợi \\ Khoa Môi Truờng \& Tài nguyên Thiên nhiên, Truờng Đại học Cần Tho \\ *Nguoòi chịu trách nhiệm về bài viết: Mai Xuân (email: maixuanks@gmail.com)
}

\section{Thông tin chung:}

Ngày nhận bài: 12/04/2021

Ngày nhận bài sủa: 27/09/2021

Ngày duyệt đăng: 15/11/2021

Title:

Assessing drought situation in Ben Tre province

\section{Tù khóa:}

Chỉ số khô hạn SPI, phưong pháp nọi suy IDW, thưc trang khô hạn, tỉnh Bến Tre

\section{Keywords:}

Ben Tre province, drought situation, internal method (IDW), standardized precipitation index

\begin{abstract}
The study aims to build a map and assess the drought situation for agricultural production in Ben Tre province in the period 2015 - 2019. The data on weather conditions were collected at the Ben Tre Hydrometeorological Station; the Inverse Distance Weighted method (IDW) was used to build drought maps; the level of impact of drought is assessed based on the Standardized Precipitation Index (SPI). The study results showed that Ben Tre province has 4 zones of drought levels: heavy, medium, light and non-drought. The situation of heavy drought zone and medium drought zone were expressed the most in the period 2015 - 2016, the other years are light drought. However, the drought area in 2019 accounted for the highest, decrease in the following years 2017, 2016, 2015, 2018. Drought has been impacting of farming system in Ben Tre province. Therefore, it is necessary to have professional assessments on the effects of drought on agricultural production and land in order to have reasonable and sustainable land use orientations.
\end{abstract}

\section{TÓM TẮT}

Điều kiện khô hạn trong giai đoạn 2015 - 2019 được đánh giá trong nghiên cưu nhằm phuc vu sản xuất nông nghiệp trên địa bàn tỉnh Bến Tre. Các dũ liệu về điều kiện thời tiết được thu thập tại Đài Khi turợng Thủy văn Bến Tre; phuoong pháp nọi suy IDW (Inverse Distance Weighted) được áp dụng để xây dưng bản đồ khô hạn; mưc độ ảnh huởng của khô hạn được đánh giá dựa vào chỉ số SPI (Standardized Precipitation Index). Kết quả nghiên cứu cho thấy Bến Tre có 4 vùng hạn theo các mức độ nặng, trung bình, nhe và không hạn. Mức độ hạn nặng và trung bình cao nhất năm 2015, 2016; các năm còn lại hạn ở mức nhẹ. Tuy nhiên, diện tích khô hạn năm 2019 là cao nhất và giảm dần theo năm 2017, 2016, 2015, 2018. Khô hạn đã và đang ảnh hưởng đến các mô hình canh tác nông nghiệp ở tỉnh Bến Tre. Vì vậy, nghiên cưu thêm về ảnh huởng của khô hạn đến sản xuất nông nghiệp, có nhũng định huớng sủ dụng đẩt hợp lý và bền vũng trong điều kiện ở tỉnh Bến Tre là cần thiết.

\section{GIỚI THIỆ}

Các hiện tượng thời tiết cực đoan do biến đổi khí hậu gây ra như: khô hạn, lũ lụt, nước biển dâng và xâm nhập mặn đang không ngừng gia tăng tại nhiều nơi trên thế giới. Đặc biệt là khô hạn đã xảy ra trên diện rộng, làm ảnh hưởng đến các hoạt động sản xuất nông nghiệp, gây thiệt hại lớn về con người và nền kinh tế (Wu \& Wilhite, 2004). Đồng bằng sông Cửu Long là vùng sản xuất nông nghiệp trọng điểm 
của cả nước đã và đang bị ảnh hưởng của những hiện tượng thời tiết cực đoan này và ngày càng trở nên nghiêm trọng (Lê Quang Trí, 2016). Sự khô hạn cũng dẫn đến việc thay đổi một số đặc tính đất đai, đất bị suy thoái về mặt vật lý và suy thoái lớp phủ thực vật. Nếu tình trạng khô hạn kéo dài sẽ dẫn đến một số chỉ tiêu về chất lượng đất đai bị thay đổi, làm ảnh hưởng đến hiệu quả sử dụng của các mô hình canh tác nông nghiệp (Lê Văn Khoa, 2013). Bến Tre là tỉnh ở ven biển phía Đông Đồng bằng sông Cửu Long đã và đang đối mặt với tình trạng khô hạn và ngày càng trở nên nghiêm trọng hơn, ảnh hưởng trực tiếp đến tài nguyên đất đai, đất mất kết cấu, khô cứng, nứt nẻ và chuyển biến theo chiều hướng xấu (Uỷ ban nhân dân tỉnh Bến Tre, 2019). Do đó, việc nghiên cứu các khía cạnh của khô hạn tại tỉnh Bến Tre để tìm hiểu những ảnh hưởng có thể xảy ra của khô hạn đối với các hoạt động sản xuất nông nghiệp là hết sức cần thiết; đồng thời, giúp cho các nhà quản lý hoạch định chiến lược sử dụng đất cũng như định hướng cơ cấu cây trồng hợp lý cho địa phương.

Hiện tượng xâm nhập mặn và khô hạn đã xảy ra trên địa bàn tỉnh Bến Tre qua nhiều năm, đặc biệt là giai đoạn 2015 đến 2019 đã ảnh hưởng không nhỏ đến sản xuất và đời sống của người dân. Vì thế, mục tiêu của nghiên cứu là đánh giá thực trạng khô hạn tại tỉnh Bển Tre trong giai đoạn từ năm 2015 đển năm 2019 nhằm phục vụ cho sản xuất nông nghiệp trong điều kiện tỉnh Bến Tre.

\section{PHƯƠNG PHÁP NGHIÊN CÚU}

\subsection{Phương pháp thu thập số liệu}

Hiện tượng khô hạn trên địa bàn tỉnh Bến Tre đã xảy ra liên tục và gây ảnh hưởng lớn đến sản xuất. Vì thế, các số liệu, báo cáo về tình hình khô hạn trong giai đoạn từ năm 2015 đến năm 2019 được thu thập. Các số liệu bao gồm tọa độ các điểm quan trắc và các dữ liệu thực đo của các điều kiện thời tiết như: nhiệt độ, lượng mưa (lượng mưa hiện tại và lượng mưa trung bình nhiều năm), lượng nước bốc hơi trong không khí, độ ẩm không khí được thu thập tại 9 trạm quan trắc thuộc Đài Khí tượng Thủy văn (KTTV) tỉnh Bến Tre dùng để tính toán chỉ số khô hạn SPI (Standardized Precipitation Index) và nội suy để xây dựng bản đồ đánh giá mức độ khô hạn trên địa bàn tỉnh Bến Tre.

Ngoài ra, các loại bản đồ hành chính, bản đồ hiện trạng sử dụng đất tỷ lệ $1 / 50.000$ được cung cấp bởi Sở Tài nguyên và Môi trường tỉnh Bến Tre, làm cơ sở cho việc nội suy xác định thực trạng các khu vực bị ảnh hưởng bởi khô hạn tại vùng nghiên cứu.

\subsection{Phương pháp đánh giá mức độ khô hạn}

Sử dụng công thức đánh giá chỉ số khô hạn SPI của Viện Khoa học Khí tượng Thủy văn và Môi trường năm 2010 để tính toán chỉ số khô hạn và đánh giá mức độ khô hạn tại địa bàn nghiên cứu. Chỉ số SPI được tính toán theo công thức:

$$
S P I=\frac{X-\bar{X}}{\sigma}
$$

Trong đó:

$\sigma$ là khoảng lệch tiêu chuẩn của lượng mưa khoảng thời gian $\mathrm{i}$.

$\mathrm{X}$ là lượng mưa trong khoảng thời gian $\mathrm{i}$

$\bar{X}$ là lượng mưa trung bình trong khoảng thời gian i.

Chỉ số SPI trong công thức trên, biến động trong khoảng từ -3 đến +3 . Các chỉ số SPI mang dấu âm (-) thể hiện sự thiếu hụt lượng mưa so với mức trung bình nhiều năm, đồng nghĩa với việc các khu vực này bị ảnh hưởng bởi khô hạn. Khi giá trị SPI mang dấu dương $(+)$ thể hiện tình trạng thừa ẩm, tức là lượng mưa cao hơn so với trung bình nhiều năm. Để đánh giá mức độ hạn khí tượng, ngưỡng chỉ tiêu hạn được thể hiện trong Bảng 1 .

Bảng 1. Thang đánh giá mức độ khô hạn theo chỉ số SPI (tần suất các mức độ hạn theo hàm phân phối chuẩn tắc)

\begin{tabular}{lll}
\hline Chỉ số SPI & Mức độ hạn & SPI \\
\hline \multirow{2}{*}{ SPI $\leq-2,0$} & Hạn nặng & $-3,0$ \\
& & $-2,5$ \\
$-2,0<\mathrm{SPI} \leq-1,5$ & Hạn trung bình & $-2,0$ \\
$-1,5<\mathrm{SPI} \leq-1,0$ & Hạn nhẹ & $-1,0$ \\
& & $-0,5$ \\
$-1,0<\mathrm{SPI}<1,0$ & Bình thường & 0,0 \\
& & 0,5 \\
$1,0 \leq \mathrm{SPI}<1,5$ & Ầm & 1,0 \\
$1,5 \leq \mathrm{SPI}<2,0$ & Rất ẩm & 1,5 \\
& & 2,0 \\
$\geq 2,0$ & \multirow{2}{*}{ Úng } & 2,5 \\
& & 3,0 \\
\hline
\end{tabular}

Nguồn: Viện Khoa học Khi tuợng Thủy văn và Môi trừ̀ng, 2010.

\subsection{Phương pháp xây dựng bản đồ khô hạn}

Trong nghiên cứu, các số liệu đã được đo đạc qua các năm 2015, 2016, 2017, 2018, 2019 được sử dụng. Vì các dữ liệu có liên quan đến khô hạn chỉ 
xác định được tại các điểm quan trắc nên phương pháp nội suy được lựa chọn để có thể xác định một cách tương đối các khoảng cách của các vùng khô hạn và thành lập bản đồ khô hạn trên địa bàn tỉnh. Đây là phương án tốt nhất có thể thực hiện được. Do đó, nghiên cứu lựa chọn sử dụng phương pháp nội suy IDW (Inverse Distance Weighted) của Watson and Philip (1985) chạy trên nền của phần mềm ArcGIS 10.5 để xây dựng bản đồ khô hạn trên địa bàn nghiên cứu. Đây là phương pháp xác định giá trị của các điểm lân cận chưa biết bằng cách tính giá trị trung bình trọng số khoảng cách của các điểm mẫu đã biết trước đó. Các điểm lân cận càng gần điểm đã biết thì càng có khả năng ảnh hưởng nhiều hơn.

Dựa vào chỉ số khô hạn SPI đã tính toán trong khoảng thời gian từ năm 2015 đến năm 2019, kêt hợp với tọa độ của 9 trạm quan trắc, việc nội suy được tiến hành để xây dựng bản đồ khô hạn cho từng năm trên địa bàn nghiên cứu. Phương pháp chồng lấp bản đồ được sử dụng để xác định các vùng biến động về khô hạn trong giai đoạn từ năm 2015 đến năm 2019.

\subsection{Phương pháp xử lý số liệu}

Các số liệu được xử lý và tính toán bằng phần mềm Excel với phương pháp thống kê mô tả.

\section{KẾT QUẢ VÀ THẢO LUẬN}

\subsection{Kết quả tính toán chỉ số khô hạn qua các năm từ 2015 đến 2019 ở tỉnh Bến Tre}

Tình hình khô hạn giai đoạn 2015 - 2019 trên địa bàn tỉnh Bến Tre được đánh giá căn cứ vào chỉ số khô hạn SPI được tính từ chuỗi mưa nhiều năm đưa về dạng hàm phân bố chuẩn tắc của số liệu mưa ứng với một khoảng thời gian khác nhau và tương ứng với tình hình khô hạn trong khoảng thời gian đó.

Kết quả tính toán chỉ số SPI trong giai đoạn này cho thấy tỉnh Bến Tre nằm trong 4 mức độ hạn là vùng hạn trung bình - nặng, vùng hạn nhẹ, vùng bình thường và vùng ẩm. Các số liệu tính toán chi tiết chỉ số SPI qua các năm tại các trạm đo của các đơn vị hành chính cấp huyện trên địa bàn tỉnh Bến Tre được trình bày trong Bảng 2 .

Bảng 2. Chỉ số SPI tại các trạm qua các năm ở tỉnh Bến Tre

\begin{tabular}{|c|c|c|c|c|c|c|c|c|c|}
\hline Năm Trạm*/SPI & $\begin{array}{c}\text { Bến } \\
\text { Tre } \\
\text { Tp.BT }\end{array}$ & $\begin{array}{c}\text { Tam } \\
\text { Phước } \\
\text { H.CT }\end{array}$ & $\begin{array}{c}\text { Thới } \\
\text { Lai } \\
\text { H.BĐ }\end{array}$ & $\begin{array}{l}\text { Chơ } \\
\text { Lách } \\
\text { H.CL }\end{array}$ & $\begin{array}{c}\text { Bình } \\
\text { Đại } \\
\text { H.BĐ }\end{array}$ & $\begin{array}{l}\text { Giồng } \\
\text { Trôm } \\
\text { H.GT }\end{array}$ & $\begin{array}{c}\text { An } \\
\text { Định } \\
\text { H.MCN }\end{array}$ & $\begin{array}{c}\text { Ba } \\
\text { Tri } \\
\text { H.BT }\end{array}$ & $\begin{array}{c}\text { Bến } \\
\text { Trại } \\
\text { H.TP }\end{array}$ \\
\hline \multirow{2}{*}{ Năm 2015} & -1 & -1 & $-1,5$ & \multirow{2}{*}{1} & 0,5 & -2 & -1 & $-1,5$ & -1 \\
\hline & 1 & 1 & 1 & & 1 & 1 & 1 & 1 & 0,5 \\
\hline \multirow{2}{*}{ Năm 2016} & -1 & -1 & -2 & \multirow{2}{*}{1} & -1 & $-1,5$ & $-0,5$ & -2 & $-1,5$ \\
\hline & $-0,5$ & 1 & -1 & & $-0,5$ & $-0,5$ & 1 & -1 & $-0,5$ \\
\hline \multirow{2}{*}{ Năm 2017} & -1 & -1 & $-1,5$ & \multirow{2}{*}{1} & $-0,5$ & -1 & $-0,5$ & -1 & -1 \\
\hline & 1 & 1 & 0,5 & & 0,5 & 1 & 1 & -1 & $-0,5$ \\
\hline \multirow{2}{*}{ Năm 2018} & -1 & -1 & -1 & \multirow{2}{*}{1} & 0,5 & -1 & $-0,5$ & -1 & -1 \\
\hline & 1 & 1 & 1 & & 1 & 1 & 1 & 1 & 1 \\
\hline \multirow{2}{*}{ Năm 2019} & -1 & -1 & $-1,5$ & 0,5 & -1 & -1 & \multirow{2}{*}{-1} & -1 & \multirow{2}{*}{-1} \\
\hline & -1 & 1 & -1 & 1 & 1 & 1 & & 1 & \\
\hline
\end{tabular}

* Ghi chú: Các trạm quan trắc và địa điểm đặt trạm gồm: Bến Tre (thành phố Bến Tre (Tp.BT)), Tam Phuoóc (huyện Châu Thành (H.CT)), Thới Lai (huyện Bình Đại (H.BĐ)), Chọ Lách (huyện Chọ Lách (H.CL)), Bình Đại (huyện Bình Đại (H.BĐ)), Giồng Trôm (huyện Giồng Trôm H.GT)), An Định (huyện Mỏ Cày Nam (H.MCN)), Ba Tri (huyện Ba Tri (H.BT)), Bến Trại (huyện Thạnh Phú (H.TP)).

Kết quả tính toán chỉ số khô hạn (SPI) trong Bảng 2 cho thấy giai đoạn từ năm 2015 đến năm 2019 khô hạn xảy ra ở hầu hết ở các huyện trên địa bàn tỉnh Bến Tre với chỉ số SPI trong khoảng từ -2 đến -1 (hạn nặng đến hạn nhẹ), trừ huyện Chợ Lách là không hạn.

Khô hạn có xu hướng biến động tăng giảm qua từng năm. Các năm 2015, 2016, 2017 và 2019 có mức khô hạn từ trung bình đến hạn nặng, riêng năm 2018 khô hạn chỉ ở mức độ nhẹ. Trong đó, khô hạn ở mức nặng chỉ xảy ra trên địa bàn huyện Giồng Trôm (năm 2015), huyện Bình Đại và huyện Ba Tri (năm 2016). Khô hạn ở mức trung bình xảy ra ở huyện Bình Đại và huyện Ba Tri (năm 2015), huyện Giồng Trôm và huyện Thạnh Phú (năm 2016), huyện Bình Đại (năm 2017 và năm 2019). Các huyện còn lại trong tỉnh có mức độ khô hạn nhẹ, riêng huyện Chợ Lách và một phần của thành phố Bến Tre không bị ảnh hưởng bởi khô hạn.

Kết quả này cũng phù hợp với kết quả báo cáo quan trắc lượng mưa của Đài KTTV Bến Tre, khi 
năm 2015 và năm 2016 có đến 4 tháng không mưa và khi mưa thì lượng mưa cũng phân bố không đều, chủ yếu là vào các tháng 8,9 và 10 . Năm 2017 và 2019 đều có 2 tháng không mưa và khi mưa thì lượng mưa chỉ tập trung vào các tháng 7,8 và 10 . Riêng năm 2018, mưa ở tất cả các tháng, tuy lượng mưa ở mùa khô không lớn nhưng cũng có sự chênh lệch tương đối so với trung bình nhiều năm.

Ngoài ra, nghiên cứu còn khảo sát thực tế để điều tra, phỏng vấn 210 nông hộ đang canh tác các kiểu sử dụng đất, sử dụng nước ngọt. Kết quả các nông hộ đều xác định trong giai đoạn này, tình trạng mưa - nắng biến động thất thường, với các tháng không mưa biến động trong khoảng từ 2 đến 5 tháng tùy theo năm hoặc có mưa nhưng lượng mưa rất ít, hầu như không đáng kể. Điều này kết hợp với tình trạng mặn xâm nhập sâu vào nội đồng làm thiếu nước ngọt nghiêm trọng để phục vụ sản xuất nông nghiệp, đã và đang ảnh hưởng không nhỏ đến năng suất của các mô hình canh tác của người dân. Điển hình là cây lúa không phát triển hoặc không thể làm đòng, dừa bị teo trái không bán được hoặc nếu có bán thì vẫn bị thương lái ép giá, các loại cây ăn trái sẽ xảy ra tình trạng cháy bông khi gặp nắng hạn.

\subsection{Kết quả xây dựng bản đồ khô hạn tỉnh Bến Tre qua các năm từ năm 2015 đến năm 2019}

Kết hợp chỉ số khô hạn SPI đã tính toán được với phương pháp nội suy IDW, bản đồ khô hạn qua các năm từ năm 2015 đến năm 2019 được xây dựng để xác định thực trạng vùng bị khô hạn trên địa bàn tỉnh Bến Tre. Dựa trên các số liệu thu thập được về diện tích tự nhiên (DTTN) trên cơ sở khoanh đất của bản đồ hiện trạng sử dụng đất, bản đồ hành chính trên địa bàn tỉnh so sánh với diện tích của các khoanh đất bị ảnh hưởng bởi khô hạn cho thấy diễn biến khô hạn có xu hướng giảm về mức độ khô hạn nhưng tăng về diện tích ảnh hưởng.

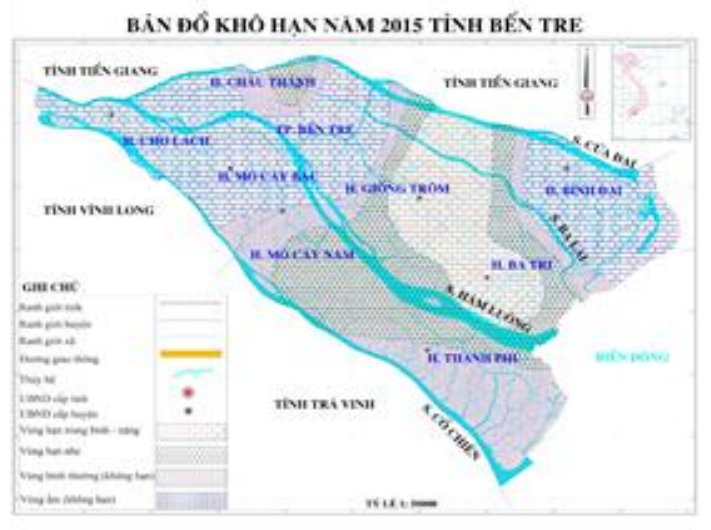

Hình 1. Bản đồ khô hạn năm 2015 tỉnh Bến Tre

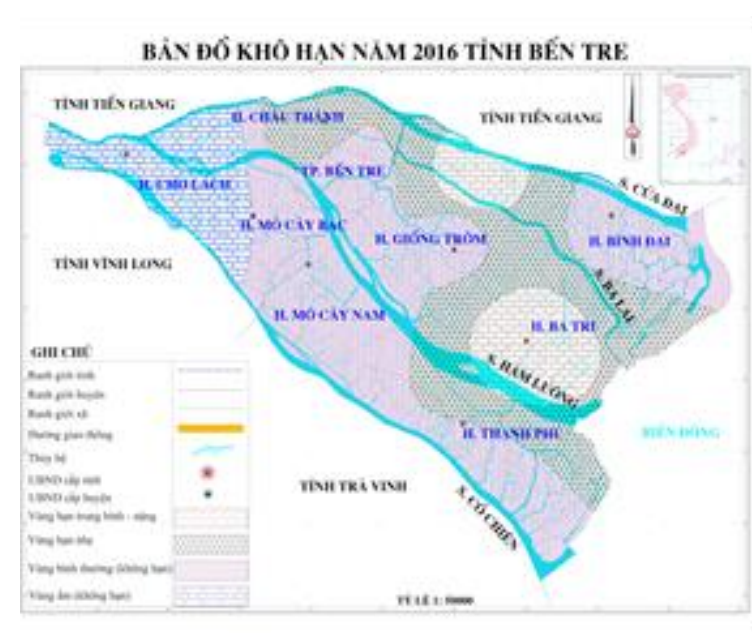

Hình 2. Bản đồ khô hạn năm 2016 tỉnh Bến Tre

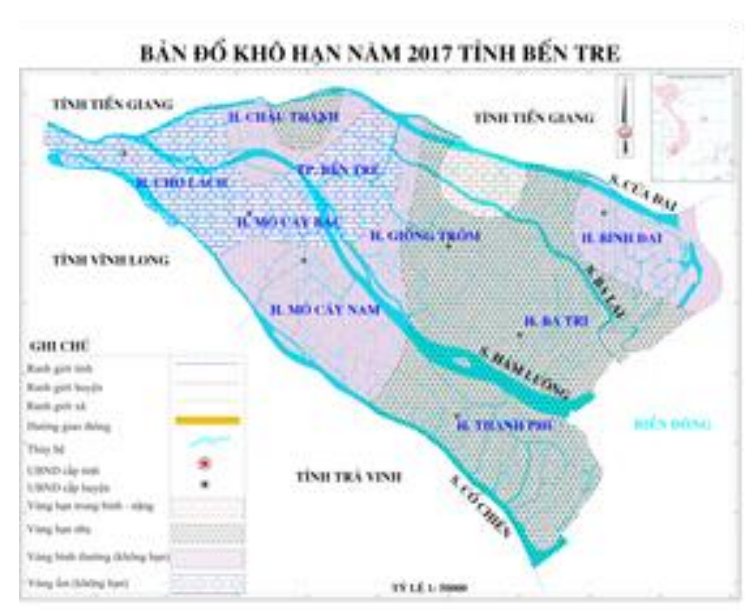

Hình 3. Bản đồ khô hạn năm 2017 tỉnh Bến Tre

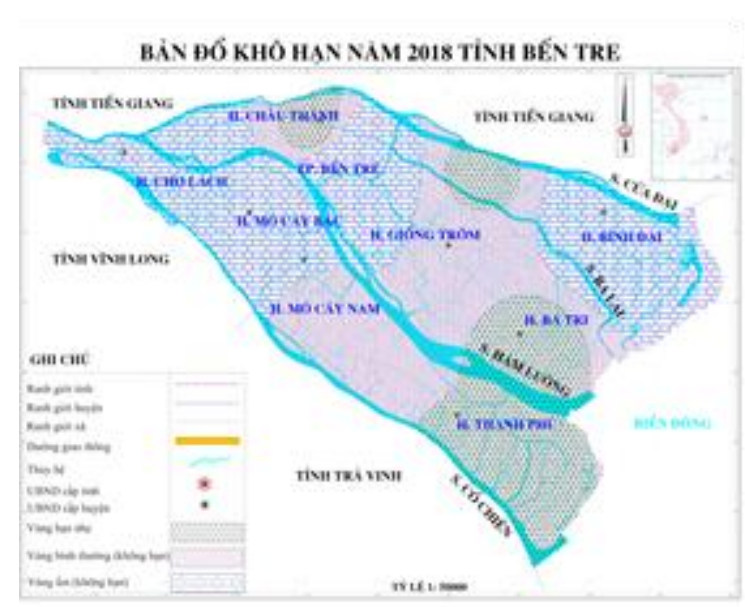

Hình 4. Bản đồ khô hạn năm 2018 tỉnh Bến Tre 


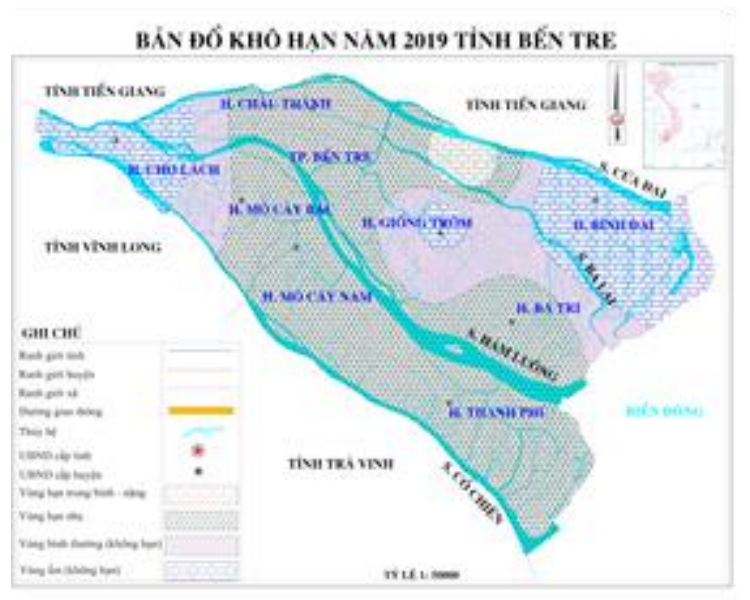

\section{Hình 5. Bản đồ khô hạn năm 2019 tỉnh Bến Tre}

Nguyên nhân chính xảy ra tình trạng khô hạn là do mùa mưa đến muộn và kết thúc sớm hơn so với trung bình nhiều năm . Đồng thời, lượng mưa tại khu vực nghiên cứu cũng ở mức thấp so với trung bình nhiều năm khoảng $20-40 \%$, làm cho tình hình khô hạn cũng trở nên nghiêm trọng hơn (Đài KTTV tỉnh Bến Tre, 2015, 2016, 2017, 2018 2019). Kết quả xây dựng bản đồ khô hạn trong giai đoạn này cho thấy diện tích ảnh hưởng bởi khô hạn tương đối cao, biến động từ 25 - đến $63 \%$ DTTN và có xu hướng biến động tăng - giảm qua các năm. Kết quả xây dựng bản đồ khô hạn từ năm 2015 đến năm 2019 tỉnh Bến Tre được trình bày từ Hình 1 đến Hình 5 .

\section{3. Đánh giá thực trạng khô hạn tỉnh Bến Tre qua các năm từ $2015-2019$}

Trong giai đoạn từ năm 2015 đến năm 2019, tình hình khô hạn trên địa bàn tỉnh tuy có giảm về mức độ ảnh hưởng nhưng tăng về diện tích ảnh hưởng trên tổng DTTN và có sự biến động giữa các năm là tương đối lớn.

Đáng kể nhất là mùa khô năm 2019, diện tích bị ảnh hưởng bởi khô hạn là 151.776 ha, chiếm khoảng $63 \%$ DTTN toàn tỉnh. Đây là năm khô hạn ảnh hưởng nhiều nhất trong giai đoạn này. Kế đến là năm 2017, diện tích ảnh hưởng bởi khô hạn chiếm 52\% DTTN, khoảng 124.048 ha. Các năm còn lại bị khô hạn ảnh hưởng nhỏ hơn $50 \%$ DTTN, với các tỷ lệ lần lượt 43\% DTTN vào năm $2016,41 \%$ DTTN vào năm 2015 và $25 \%$ DTTN vào năm 2018 . Tuy nhiên, diện tích ảnh hưởng bởi hạn ở mức trung bình - nặng vào năm 2015 và năm 2016 chiếm cao nhất so với các năm còn lại. Trong đó, cao nhất là năm 2015 với diện tích hạn trung bình - nặng là 37.480 ha, chiếm 16\% DTTN; kế đển là năm 2016 với diện tích là 28.508 ha, chiếm $12 \%$ DTTN. Đối với các năm 2017 và năm 2019, diện tích ảnh hưởng không đáng kể, chỉ chiếm tỷ lệ lần lượt tương ứng là $4 \%$ và $2 \%$ so với DTTN. Năm 2018 không bị ảnh hưởng bởi hạn trung bình - nặng. Trong khi đó, hạn ở mức nhẹ vào năm 2019 có diện tích ảnh hưởng lên đến 146.288 ha, chiếm $61 \%$ DTTN; kế đến là năm 2017 với tỷ lệ diện tích ảnh hưởng chiếm $48 \%$ DTTN; năm 2016, diện tích ảnh hưởng chiếm tỷ lệ $31 \%$ DTTN; các năm 2015 và năm 2018 có diện tích ảnh hưởng thấp nhất, với tỷ lệ tương ứng $25 \%$ DTTN (Hình 6).

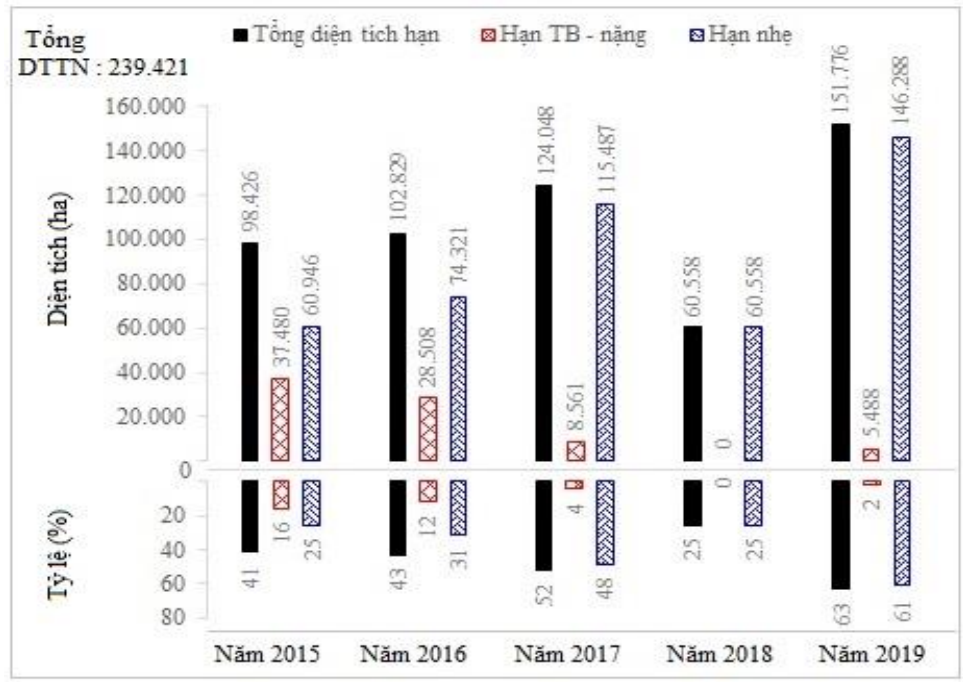

Hình 6. Diện tích khô hạn, cơ cấu tỷ lệ khô hạn ảnh hưởng đến tỉnh Bến Tre trong giai đoạn từ năm 2015 đến năm 2019 
Kết quả phân tích tại Hình 6 cho thấy tình hình khô hạn ảnh hưởng đến tỉnh Bến Tre từ năm 2015 đến năm 2019 có thể chia làm 3 giai đoạn:

Giai đoạn 1 - từ năm 2015 đến năm 2017: Đây là giai đoạn mà khô hạn ảnh hưởng tăng mạnh đến diện tích của tỉnh, tăng từ $41 \%$ lên $52 \%$ DTTN (tỷ lệ tăng khoảng 25\%). Tuy diện tích ảnh hưởng bởi khô hạn có tăng nhưng mức độ khô hạn ở mức trung bình - nặng lại giảm từ $16 \%$ giảm xuống còn $4 \%$ (tỷ lệ giảm khoảng 75\%); chỉ có mức độ hạn nhẹ tăng mạnh từ $25 \%$ lên $48 \%$ DTTN (tỷ lệ tăng khoảng $92 \%)$.

Bảng 3. Diện tích ảnh hưởng bởi khô hạn giai đoạn 2015 - 2019

\begin{tabular}{|c|c|c|c|c|c|c|c|c|c|c|c|c|}
\hline \multirow[b]{3}{*}{ TT } & \multirow[b]{3}{*}{ Đơn vị } & \multirow{3}{*}{$\begin{array}{c}\text { Diện } \\
\text { tích } \\
\text { tự } \\
\text { nhiên } \\
\text { (ha) }\end{array}$} & \multicolumn{10}{|c|}{ Diện tích ảnh hưởng bởi khô hạn } \\
\hline & & & \multicolumn{2}{|c|}{ Năm 2015} & \multicolumn{2}{|c|}{ Năm 2016} & \multicolumn{2}{|c|}{ Năm 2017} & \multicolumn{2}{|c|}{ Năm 2018} & \multicolumn{2}{|c|}{ Năm 2019} \\
\hline & & & $\begin{array}{l}\text { Diện } \\
\text { tích } \\
\text { (ha) }\end{array}$ & $\begin{array}{l}\text { Tỷ } \\
\text { lệ } \\
(\%)\end{array}$ & $\begin{array}{l}\text { Diện } \\
\text { tích } \\
\text { (ha) }\end{array}$ & $\begin{array}{l}\text { Tỷ } \\
\text { lệ } \\
(\%)\end{array}$ & $\begin{array}{l}\text { Diện } \\
\text { tích } \\
\text { (ha) }\end{array}$ & $\begin{array}{l}\text { Tỷ } \\
\text { lệ } \\
(\%)\end{array}$ & $\begin{array}{l}\text { Diện } \\
\text { tích } \\
\text { (ha) }\end{array}$ & $\begin{array}{l}\text { Tỷ } \\
\text { lệ } \\
(\%)\end{array}$ & $\begin{array}{l}\text { Diện } \\
\text { tích } \\
\text { (ha) }\end{array}$ & $\begin{array}{l}\text { Tỷ } \\
\text { lệ } \\
(\%)\end{array}$ \\
\hline \multirow{4}{*}{$*$} & Tỉnh Bến Tre & 239.421 & 98.426 & 41 & 102.829 & 43 & 124.048 & 52 & 60.558 & 25 & 151.776 & 63 \\
\hline & Hạn trung bình & & 37.480 & 16 & 28.508 & 12 & 8.561 & 4 & 0 & 0 & 5.488 & 2 \\
\hline & Hạn nhẹ & & 60.946 & 25 & 74.321 & 31 & 115.487 & 48 & 60.558 & 25 & 146.288 & 61 \\
\hline & Tp. Bến Tre & 7.062 & 38 & 1 & 1.245 & 18 & 412 & 6 & 388 & 5 & 7.062 & 100 \\
\hline \multirow[t]{3}{*}{1} & Hạn trung bìn & & 0 & 0 & 0 & 0 & 0 & 0 & 0 & 0 & 0 & 0 \\
\hline & Hạn nhẹ & & 38 & 1 & 1.245 & 18 & 412 & 6 & 388 & 5 & 7.062 & 100 \\
\hline & H. Châu Thành & 22.489 & 3.290 & 15 & 10.524 & 47 & 4.971 & 22 & 4.423 & 20 & 15.008 & 67 \\
\hline \multirow[t]{3}{*}{2} & Hạn trung bình - & & 0 & 0 & 0 & 0 & 0 & 0 & 0 & 0 & 0 & 0 \\
\hline & Hạn nhẹ & & 3.290 & 15 & 10.524 & 47 & 4.971 & 22 & 4.423 & 20 & 15.008 & 67 \\
\hline & H. Chợ L & 16.906 & 0 & 0 & 0 & 0 & 0 & 0 &  & 0 & 0 & U \\
\hline \multirow[t]{3}{*}{3} & Hạn & & 0 & 0 & 0 & 0 & 0 & 0 & 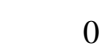 & 0 & 0 & 0 \\
\hline & Hạn & & 0 & 0 & 0 & 0 & 0 & 0 & 0 & 0 & 0 & 0 \\
\hline & H. Giồng T & 31.259 & 20.393 & 65 & 11.056 & 35 & 17.584 & 56 & 923 & 3 & 15.788 & 51 \\
\hline \multirow[t]{3}{*}{4} & Hạn trung bi & & 12.034 & 38 & 1.173 & 4 & 1.763 & 6 & 0 & 0 & 311 & 1 \\
\hline & Hạn n & & 8.359 & 27 & 9.883 & 32 & 15.821 & 51 & 923 & 3 & 15.477 & 50 \\
\hline & H. Bình Đại & 42.731 & 10.737 & 25 & 25.750 & 60 & 24.637 & 58 & 5.839 & 14 & 11.273 & 26 \\
\hline \multirow[t]{3}{*}{5} & Hạn trung bình - nặng & & 6.583 & 15 & 7.390 & 17 & 6.798 & 16 & 0 & 0 & 5.177 & 12 \\
\hline & Hạn & & 4.154 & 10 & 18.360 & 43 & 17.839 & 42 & 5.839 & 14 & 6.096 & 14 \\
\hline & H. Ba Tri & 36.724 & 34.213 & 93 & 36.724 & 100 & 36.724 & 100 & 17.192 & 47 & 22.213 & 60 \\
\hline \multirow[t]{3}{*}{6} & Hạn trung & & 18.863 & 51 & 19.250 & 52 & 0 & 0 & 0 & 0 & 0 & 0 \\
\hline & Hạn nhẹ & & 15.350 & 42 & 17.474 & 48 & 36.724 & 100 & 17.192 & 47 & 22.213 & 60 \\
\hline & H. Thạnh Phú & 42.655 & 16.307 & 38 & 17.530 & 41 & 39.720 & 93 & 31.793 & 75 & 42.655 & 100 \\
\hline \multirow[t]{3}{*}{7} & Hạn tru & & 0 & 0 & 695 & 2 & 0 & 0 & 0 & 0 & 0 & . \\
\hline & & & 16.307 & 38 & 16.835 & 39 & 39.720 & 93 & 31.793 & 75 & 42.655 & 100 \\
\hline & H. Mỏ Cày Nam & 23.077 & 13.448 & 58 & 0 & 0 & 0 & 0 & 0 & 0 & 23.077 & 100 \\
\hline \multirow[t]{3}{*}{8} & Hạn $t$ & & 0 & 0 & 0 & 0 & 0 & 0 & 0 & 0 & 0 & 0 \\
\hline & Hạn n & & 13.448 & 58 & 0 & 0 & 0 & 0 & 0 & 0 & 23.077 & 100 \\
\hline & H. Mỏ Cày Bắc & 16.518 & 0 & 0 & 0 & 0 & 0 & 0 & 0 & 0 & 14.700 & 89 \\
\hline \multirow[t]{2}{*}{9} & Hạn trung bình - nặng & & 0 & 0 & 0 & 0 & 0 & 0 & 0 & 0 & 0 & 0 \\
\hline & Hạn nhẹ & & 0 & 0 & 0 & 0 & 0 & 0 & 0 & 0 & 14.700 & 89 \\
\hline
\end{tabular}

Giai đoạn 2 - từ năm 2017 đến năm 2018: Đây là giai đoạn mà sự ảnh hưởng của khô hạn trên toàn tỉnh có xu hướng giảm về tỷ lệ diện tích ảnh hưởng, giảm từ $52 \%$ năm 2017 giảm xuống còn $25 \%$ DTTN năm 2019 (tỷ lệ giảm khoảng 52\%).Trong khi mức độ khô hạn ở mức trung bình - nặng giảm từ 4\% năm 2017 giảm xuống còn 0\% DTTN năm 2018 (tỷ lệ 
giảm $100 \%$ ) và tỷ lệ diện tích hạn nhẹ cũng giảm từ $48 \%$ còn $25 \%$ DTTN (tỷ lệ giảm khoảng $48 \%$ ).

Giai đoạn 3 - giai đoạn từ năm 2018 đến năm 2019: Đây là giai đoạn mà khô hạn ảnh hưởng tăng cả về mức độ và diện tích. Tỷ lệ diện tích ảnh hưởng tăng từ $25 \%$ lên $63 \%$ DTTN (tỷ lệ tăng khoảng $252 \%$ ), trong khi tỷ lệ diện tích hạn ở mức trung bình - nặng tăng tuyệt đối từ $0 \%$ năm 2018 lên $2 \%$ năm 2019 , diện tích hạn nhẹ cũng tăng từ $25 \%$ lên $61 \%$ DTTN (tỷ lệ tăng khoảng 244\%).

Số liệu trình bày trong Bảng 3 cho thấy có 04 đơn vị hành chính trực thuộc tỉnh Bến Tre bị ảnh hưởng bởi khô hạn với tỷ lệ 100\% DTTN, bao gồm huyện $\mathrm{Ba}$ Tri (năm 2016 và năm 2017); thành phố Bến Tre, huyện Thạnh Phú và huyện Mỏ Cày Nam (năm 2019). Trong giai đoạn từ năm 2015 đến năm 2019, xét về mặt tổng thể, có thể phân chia tình hình khô hạn ảnh hưởng trên địa bàn tỉnh Bến Tre làm 3 nhóm: nhóm thứ nhất - nhóm có tỷ lệ diện tích ảnh hưởng bởi khô hạn tăng từ đầu kỳ đến cuối kỳ của số liệu quan sát (trong đó có biến động tăng, giảm qua từng năm), có 6 đơn vị cấp huyện, bao gồm thành phố Bến Tre, huyện Châu Thành, huyện Bình Đại, huyện Thạnh Phú, huyện Mỏ Cày Nam, huyện Mỏ Cày Bắc; nhóm thứ hai - nhóm có tỷ lệ diện tích ảnh hưởng bởi khô hạn biến động tăng, giảm khác nhau qua từng năm, nhưng có xu hướng chung là giảm trên tổng thể quan sát, có 2 đơn vị cấp huyện, bao gồm các huyện Giồng Trôm và huyện $\mathrm{Ba}$ Tri; nhóm thứ ba - nhóm không ảnh hưởng bởi khô hạn là huyện Chợ Lách.

Trong giai đoạn này, xét trên tổng thể quan sát thì Ba Tri là huyện bị ảnh hưởng nhiều nhất bởi khô hạn, tuy có xu hướng giảm về mức độ khô hạn nhưng diện tích ảnh hưởng lại chiếm tỷ lệ cao. Trong đó, hạn ở mức trung bình - nặng chỉ ảnh hưởng vào năm 2015 và năm 2016, các năm còn lại chỉ hạn ở mức nhẹ. Từ năm 2015 đến năm 2017, tỷ lệ diện tích ảnh hưởng có xu hướng tăng, tỷ lệ tăng khoảng $7 \%$. Từ năm 2017 đến năm 2018, tỷ lệ diện tích ảnh hưởng giảm khoảng 53\%. Từ năm 2018 đến năm 2019, tỷ lệ diện tích ảnh hưởng tăng khoảng $27 \%$.

Kế đến là huyện Thạnh Phú, diện tích khô hạn ảnh hưởng nhìn chung có xu hướng tăng, tuy nhiên, hạn ở mức trung bình - nặng chỉ ảnh hưởng vào năm 2016, chiếm tỷ lệ $2 \%$ DTTN, các năm còn lại chỉ hạn ở mức nhẹ. Trong đó, từ năm 2015 đến năm 2017, tỷ lệ diện tích ảnh hưởng bởi khô hạn có xu hướng tăng với tỷ lệ khoảng 145\%. Từ năm 2017 đến năm 2018, tỷ lệ diện tích ảnh hưởng giảm với tỷ lệ khoảng 19\%. Đến năm 2019, tỷ lệ diện tích ảnh hưởng bởi khô hạn tăng đột ngột lên 100\% DTTN với tỷ lệ khoảng 33\% so với năm 2018.

Giồng Trôm cũng là huyện có tỷ lệ diện tích ảnh hưởng bởi khô hạn cao, giai đoạn này, tỷ lệ diện tích ảnh hưởng có xu hướng giảm về tổng diện tích và khô hạn ở mức trung bình - nặng nhưng tăng tỷ lệ diện tích về mức độ khô hạn nhẹ. Trong đó, từ năm 2015 đến năm 2016, tỷ lệ diện tích khô hạn ảnh hưởng giảm khoảng 46\%. Đến năm 2017, tỷ lệ diện tích khô hạn ảnh hưởng tăng khoảng $60 \%$ so với năm 2016, sau đó, giảm sâu vào năm 2018, khi tỷ lệ ảnh hưởng giảm tương ứng khoảng $95 \%$. Đến năm 2019, tỷ lệ diện tích ảnh hưởng đột ngột tăng cao với tổng tỷ lệ khoảng $1.600 \%$; trong khi đó tỷ lệ diện tích khô hạn tăng từ 3\% lên $50 \%$ DTTN so với năm 2018.

Tiếp theo là huyện Bình Đại, tỷ lệ diện tích ảnh hưởng bởi khô hạn có xu hướng chung cho cả giai đoạn có tăng nhưng không đáng kể. Trong đó, chỉ có năm 2018 là không bị ảnh hưởng khô hạn mức trung bình - nặng. Trong 2 năm 2015 và năm 2016, tỷ lệ diện tích bị ảnh hưởng tăng với tỷ lệ khoảng 140\%. Từ năm 2016 đến năm 2017, tỷ lệ diện tích ảnh hưởng có xu hướng giảm khoảng $3 \%$. Đến năm 2018, tỷ lệ diện tích ảnh hưởng tiếp tục giảm về diện tích và mức độ hạn. Đây cũng là năm mà hạn chỉ ảnh hưởng ở mức nhẹ, diện tích ảnh hưởng chỉ chiếm $14 \%$ DTTN, tỷ lệ giảm khoảng $76 \%$ so với năm 2017. Đến năm 2019, ảnh hưởng của khô hạn tăng lên cả về diện tích và mức độ khô hạn, tỷ lệ ảnh hưởng là $26 \%$ DTTN, tỷ lệ tăng khoảng $86 \%$ so với năm 2018.

Huyện Châu Thành cũng chịu ảnh hưởng nhiều bởi khô hạn, đặc biệt ở các năm 2016 và năm 2019 , nhưng chỉ ảnh hưởng hạn ở mức nhẹ. Trong đó, từ năm 2015 đến năm 2016, tỷ lệ diện tích ảnh hưởng bởi khô hạn tăng khoảng 213\%. Từ năm 2016 đến năm 2018, tỷ lệ diện tích ảnh hưởng có xu hướng giảm với tỷ lệ khoảng 57\%. Sau đó, từ năm 2018 đến năm 2019, tỷ lệ diện tích ảnh hưởng bởi khô hạn tăng đột ngột từ $20 \%$ lên $67 \%$ DTTN, tỷ lệ tăng khoảng $235 \%$.

Huyện Mỏ Cày Nam chỉ có 2 năm bị khô hạn ảnh hưởng, mặc dù chỉ ở mức hạn nhẹ nhưng diện tích ảnh hưởng lớn. Trong đó, năm 2015 có tỷ lệ diện tích ảnh hưởng chiếm $58 \%$ DTTN và giảm xuống $0 \%$ vào các năm 2016, 2017 và 2018; đến năm 2019 diện tích ảnh hưởng tăng đột ngột lên $100 \%$ DTTN toàn huyện.

Thành phố Bến Tre là trung tâm tỉnh lỵ của Bến Tre, cũng là đơn vị chịu ảnh hưởng của khô hạn, tuy 
chỉ ở mức độ nhẹ nhưng cũng biến động phức tạp qua từng năm. Từ năm 2015 đến năm 2016, tỷ lệ diện tích khô hạn ảnh hưởng tăng khoảng $1.800 \%$. Từ năm 2016 đến năm 2018, tỷ lệ diện tích ảnh hưởng giảm khoảng 75\%. Từ năm 2018 đến năm 2019, tỷ lệ diện tích ảnh hưởng tăng khoảng $1.900 \%$, khi tỷ lệ diện tích ảnh hưởng từ 5\% DTTN năm 2018 tăng lên $100 \%$ DTTN năm 2019 và ảnh hưởng trên toàn bộ DTTN của thành phố.

Cũng trong giai đoạn này, huyện Mỏ Cày Bắc chỉ bị ảnh hưởng bởi khô hạn vào năm 2019 với tỷ lệ 89\% DTTN, chỉ ở mức hạn nhẹ.

Huyện Chợ Lách hoàn toàn không bị ảnh hưởng bởi khô hạn trong giai đoạn này.

Nhìn chung, trong giai đoạn từ năm 2015 đến năm 2019, khô hạn đã có những ảnh hưởng nhất định trên địa bàn tỉnh Bến Tre, trừ huyện Chợ Lách thì các huyện còn lại và thành phố Bến Tre đều bị ảnh hưởng với các mức độ hạn và tỷ lệ diện tích ảnh hưởng biến động phức tạp, gây trở ngại đến các hoạt động của người dân, đặc biệt là thiếu nguồn nước phục vụ cho hoạt động sản xuất nông nghiệp. Bên cạnh đó, khô hạn cũng dẫn đến tình trạng đất bị khô cứng, nứt nẻ, mất cấu trúc; giảm năng suất cây trồng, giảm diện tích gieo trồng, giảm sản lượng cây trồng, chủ yếu là sản lượng cây lương thực; tăng chi phí sản xuất nông nghiệp, giảm thu nhập của lao động nông nghiệp; tăng giá thành và giá cả các lương thực. Vấn đề này có ảnh hưởng to lớn đến lĩnh vực môi trường, kinh tế và xã hội.

\subsection{Biến động khô hạn trong giai đoạn từ năm 2015 đến năm 2019}

Trong giai đoạn từ năm 2015 đến năm 2019, tình hình khô hạn trên địa bàn tỉnh Bến Tre biến động phức tạp và khó lường trước. Diện tích biến động vùng khô hạn tương đổi lớn. Toàn tỉnh Bến Tre chỉ có 61.745 diện tích không bị ảnh hưởng bởi khô hạn, chiếm tỷ lệ $26 \%$ DTTN, vùng ảnh hưởng bởi khô hạn là 177.676 ha, chiếm tỷ lệ $74 \%$ DTTN. Trong đó, vùng hạn không biến động trong giai đoạn này và chiếm tỷ lệ $43 \%$ DTTN với diện tích khoảng 102.204 ha, vùng hạn biến động theo xu hướng giảm chiếm 13\% DTTN với diện tích khoảng 30.460 ha, vùng hạn biến động theo xu hướng tăng chiếm $35 \%$ DTTN tương ứng với diện tích khoảng 82.760 ha (Hình 7).

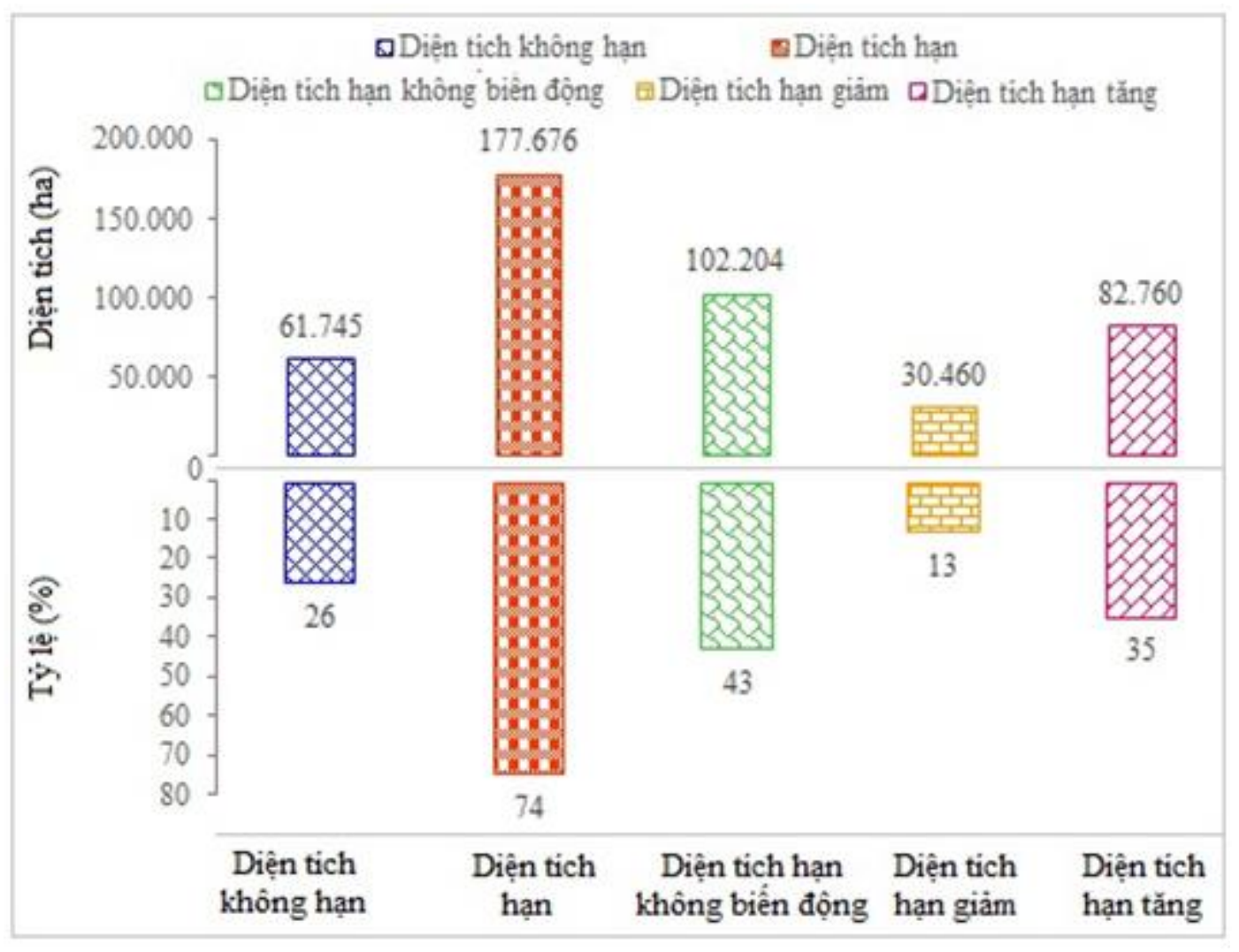

Hình 7. Biến động diện tích ảnh hưởng bởi khô hạn giai đoạn2015 - 2019 ở tỉnh Bến Tre 
Trong giai đoạn này, vùng khô hạn trên địa bàn tỉnh Bến Tre cũng biến động phức tạp. Trong năm 2015, vùng khô hạn lớn hơn 50\% DTTN tập trung ở các huyện Ba Tri, huyện Giồng Trôm và huyện Mỏ Cày Nam. Các vùng còn lại có diện tích ảnh hưởng nhỏ hơn 50\% DTTN tập trung ở các huyện Thạnh Phú, huyện Bình Đại; một phần nhỏ huyện Châu Thành, thành phố Bến Tre hoặc không hạn tại huyện Chợ Lách và huyện Mỏ Cày Bắc. Trong đó, tỷ lệ diện tích hạn trung bình - nặng chiếm 16\% DTTN toàn tỉnh và hạn nhẹ chiếm $25 \%$ DTTN toàn tỉnh. Đến năm 2019, vùng khô hạn biến động theo hướng tăng tỷ lệ diện tích ảnh hưởng của hạn nhẹ lên $61 \%$ DTTN nhưng giảm tỷ lệ diện tích của hạn ở mức trung bình - nặng còn $\%$ DTTN. Trong đó, phần hạn biến động có xu hướng tăng ở thành phố Bến Tre và các huyện Thạnh Phú, huyện Mỏ Cày Nam, huyện Mỏ Cày Bắc và huyện Châu Thành; phần hạn biến động có xu hướng giảm tại huyện Giồng Trôm và huyện $\mathrm{Ba}$ Tri (Hình 8).

\section{BẢN ĐỒ BIẾN ĐộNG KHÔ HẠN GIAI ĐOẠN 2015 - 2019 TỈNH BẾN TRE}

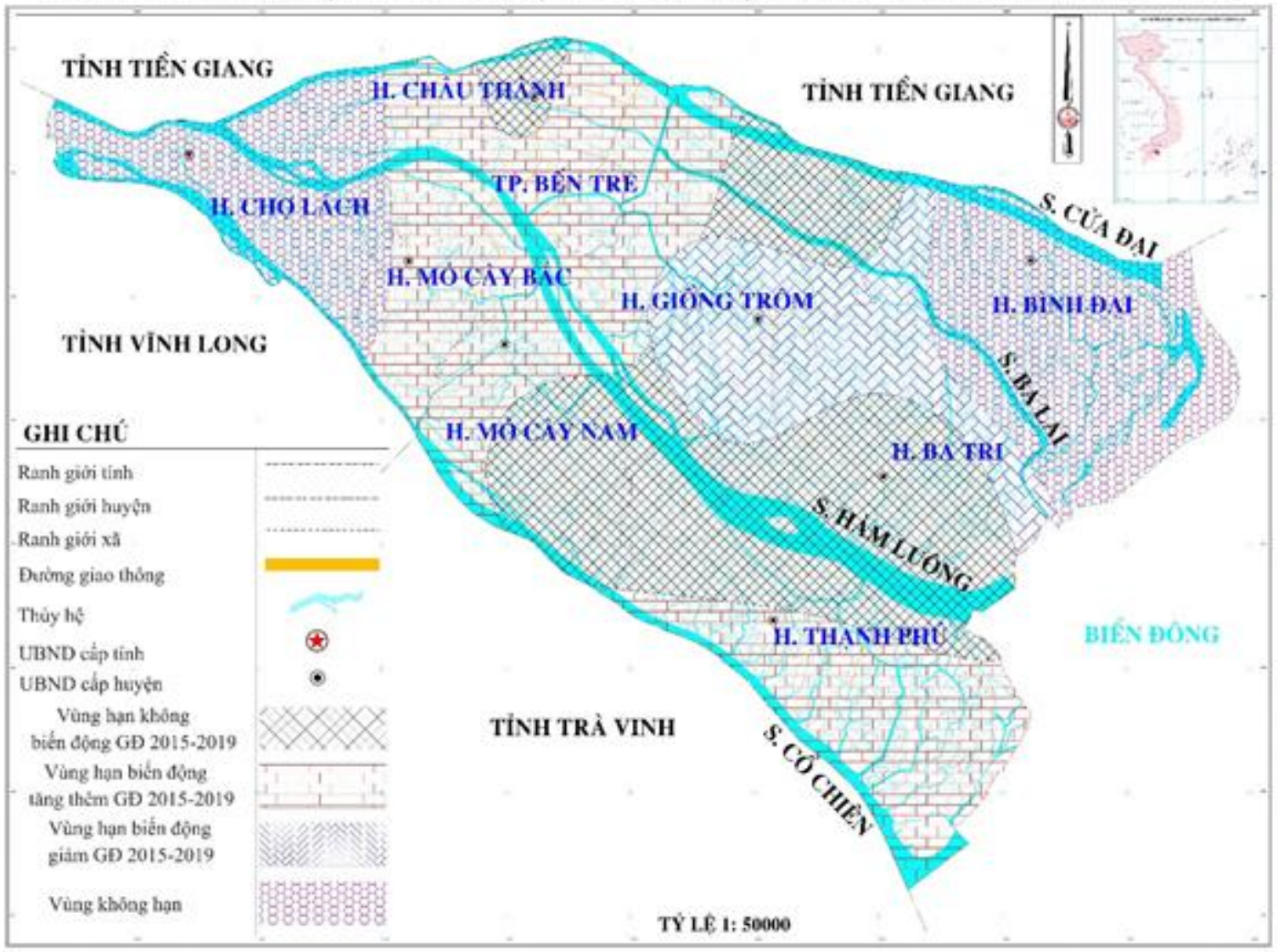

Hình 8. Bản đồ biến động khô hạn giai đoạn 2015 - 2019 ở tỉnh Bến Tre

\section{KẾT LUẬN}

Nghiên cứu đã xây dựng được bản đồ đánh giá các vùng bị ảnh hưởng bởi khô hạn. Mức độ khô hạn có sự thay đổi qua từng năm và phụ thuộc vào các điều kiện thời tiết, đặc biệt là lượng mưa trên địa bàn. Ranh giới biến động khô hạn tại các vùng có thay đổi, nhìn chung có xu hướng tăng và giảm diện tích vùng bị ảnh hưởng vào giữa năm 2015 và 2019 .
Kết quả cho thấy Bến Tre có 4 vùng hạn theo các mức độ là nặng, trung bình, nhẹ và không hạn. Mức độ hạn nặng và trung bình cao nhất năm 2015, 2016, hạn của các năm còn lại ở mức nhẹ. Diện tích hạn ở năm 2019 là cao nhất và giảm dần theo năm 2017, 2016, 2015, 2018.

Khô hạn đã và đang ảnh hưởng đến các mô hình canh tác nông nghiệp tỉnh Bến Tre. Do đó, những nghiên cứu đánh giá về ảnh hưởng của khô hạn đến 
sản xuất nông nghiệp để có những định hướng sử dụng đất hợp lý và bền vững là cần thiết.

\section{LỜI CẢM TẠ}

Xin cảm ơn Dự án Nâng cấp Trường Đại học Cần Thơ VN14-P6 bằng nguồn vốn vay $\mathrm{ODA}$ từ Chính phủ Nhật Bản đã tài trợ cho đề tài nghiên cứu này

\section{TÀI LIỆ THAM KHẢO}

Đài Khí tượng Thủy văn tỉnh Bến Tre. (2019).

Thông báo khí tượng thủy văn tỉnh Bến Tre qua các năm từ năm 2015 - 2019.

https://bentre.gov.vn/

Wu, H., \& Wilhite, D. A. (2004). An operational agricultural drought risk assessment model for Nebraska, USA. Natural Hazards, 33(1), 1-21.
Lê Văn Khoa. (2013). Giáo trình Bac màu đất và bảo tồn tài nguyên đất. Nhà xuất bản Đại học Cần Thơ

Lê Quang Trí. (2016). Tác động của biến đổi khí hậu đối với sản xuất nông nghiệp ở đồng bằng sông Cửu Long. Tạp chi Khoa học và Công nghệ Việt Nam, 8, 40-42.

Ủy ban nhân dân tỉnh Bến Tre. (2019). Báo cáo tình hình kinh tế - xã hội tỉnh Bến Tre Quý IV và năm 2019. https://bentre.gov.vn/

Viện Khoa học Khí tượng Thủy văn và Môi trường. (2010). Tài liệu hướng dẫn đánh giá tác động của biến đổi khí hậu và xác định các giải pháp thich úng. Nhà xuất bản Tài Nguyên - Môi Trường và Bản đồ Việt Nam.

Watson, D. F., Philip, G.M. (1985). A Refinement of Inverse Distance Weighted Interpolation. GeoProcessing, 2(4), 315-327. 